\title{
The Effect of Emotional Intelligence Group Training on Human and Social Capital in Isfahan University of Technology
}

\section{Batoul Tadayon Charsoughi ${ }^{1}$, Mohammad Reza Abedi ${ }^{2}$, Parisa Nilforoushan ${ }^{3}$}

${ }^{1}$ Islamic Azad University, Khomeini Shar Branch, Isfahan, Iran

${ }^{2}$ Isfahan University and Islamic Azad University, Khomeini Shar Branch, Isfahan, Iran

${ }^{3}$ Psychology Department, Isfahan University, Isfahan, Iran

E-mail address: 'bt.td20@yahoo.com

2dr.mr.abedi@gmail.com

3panilfo@yahoo.com

Keywords: emotional intelligence; human capital; social capital

\begin{abstract}
The aim of this study was to investigate the effect of emotional intelligence group training on human and social capital in the students of Isfahan University of Technology. This research was a quasi-experimental study with pretest-posttest design and control group. The research population consists of all the students of Isfahan University of Technology who have been studying in 20122013. For sampling, voluntary sampling method was used that 36 subjects were selected as the sample and were randomly divided into two groups of experiment and control. The subjects of experimental group participated in 8 sessions of 90-minute classes while the control group received no intervention. The study's tool was Mousavi Employability Questionnaire (2013). Analysis of covariance was used to analyze the data. According to the results, emotional intelligence training have had impact upon human capital $(\mathrm{P}<0.004)$. However, emotional intelligence training had no effect on social capital.
\end{abstract}

\section{INTRODUCTION}

In each community, employment and having a job is important for the people at working age. Given the outcomes of having a job, a large part of the population seeks employment. In this regard, the employed people are more healthy and satisfied with their lives. The importance of employment and its consequent effects have prompted the researchers to make effort for enhancing people employability.

Many definitions have been offered for the concept of employability. Employability is defined as one's ability to gain initial employment, job retention, job changes within the same organization, and achieve a new job when needed. This definition includes both unemployed people who are looking for a job and the employed people who are looking for a new job or want to promote their position (Hillage\& Pollard, 1998). Fugate et al (2004) describe employability as a psychosocial structure that embodies those personal characteristics that enhances adaptive cognition and behavior, and reinforces one's working relations. Since it involves those characteristics that cover the gaps between the individual and the environment, employability is considered a psychosocial structure. They define employability as one's ability in identifying and specifying career opportunities within and between organizations. According to them, employability includes the four aspects of career adaptability, personal adaptability, human capital, and social capital.

Individuals and organizations invest in the field of human and social capitals and predict its future returns in the workplace (Dess\& Shaw, 2001). One's ability to identify and realize career opportunities depends on the extent to which one is influenced by such capitals. These factors are often included in a broader concept of knowledge, skills and abilities. However, the discussion here is limited to human and social capitals since these concepts have a specific relationship with 
employability. Moreover, human and social capitals are tied to the people's career identities and are embedded in sociability structure (Fugate et al, 2004).

Social capital emanates from the social networks. It provides an interpersonal and social element for employability, transfers information, and through social networks, provides people with influence, power and information. This influence, power and information not only provide the individuals with the possibility to have access to career opportunities but also, they are important components in achieving career aspirations (Fugate, 2006). In this regard, the network's size and power are two important features of the network that determine the potentiality of the created influence and information. The breadth and diversity of an individual network is probably proportional to the amount of information and influence in the network, as well as to the usefulness and influence of the information (Seibret et al, 2001).

The benefits of social capital and its impact on the employability are demonstrated in employment-related behaviors of individuals. Individuals with a well-developed social capital, not only benefit from more formal job searching networks (like a company that supports tender services) but also from informal job searching networks as well (e.g a friend of friend). In this regard, Boxman, Graaf and Flap (1991) found out that top managers often search for jobs through informal networks. They also found that social capital has a positive and independent impact on wages that is higher and beyond human capital. Social networks can increase one's ability in identifying and understanding career opportunities between organizations and industries and during the career (Fugate, 2008).

An employee's ability to understand job opportunities in the labor market is heavily influenced by his human capital. Human capital refers to a set of factors that affect the variables associated with one's career advancements. These factors include age and education, experience and job training, job performance and organizational tenure, emotional intelligence, cognitive abilities and knowledge, and skills and abilities that are created by such factors. Among human capital factors, education and experience are the strongest predictors of career advancement (Fugate et al, 2004). In many types of employments, educational levels, even if they are not necessary, are preferred. These educational levels include compulsory education, associate degree, bachelor degree, certificate for a specific job and professional degrees. In fact, some researchers believe that the value and rate of return for education is measurable (Goleman, 1988).

Experience is also very important. Experience often leads to different levels of skills and tacit knowledge which make the experienced person seem more attractive and prospective in the eyes of employers. In modern workplaces, experience is shown through portable skills and not through industry or exposure to a specific occupation. Portable skills include knowledge, abilities and skills which are obtained from very different areas and are transferable to other areas. Employees often choose individuals according to their experiences and experience is associated with productivity and rewards. In short, human capital refers to one's ability in meeting performance expectations in a particular profession (Protess, 1998).

Therefore, one's level of education and experience are powerful predictors for career advancement. Human capital will help both individual and organizational adaptability. Furthermore, investment in human capital throughout a person's career is an adaptive orientation and a commitment to continuous learning that will lead to further strengthening of employability (Fugate, 2004).

Researchers have shown that according to some factors, people with high IQ are not necessarily successful in their lives, while those with an average IQ may be placed on the road to success. These factors include another dimension of intelligence called as emotional intelligence by Goleman. The concept of emotional intelligence was first proposed by Salovay and Mayer as a form of social intelligence. Salovay used this concept for describing and understanding of people's feeling, sympathy with the feelings of others, and the ability in optimal management of temperament. In their definition, they introduced emotional intelligence as the ability to process emotional information including the proper assessment of one's and others' emotions, appropriate 
expression of emotions, and adaptive regulation of emotions so that it leads to the improvement of flow of life (Nouri-Emamzadeh, 2009).

In 1990, Goleman argued that emotional intelligence can be used to identify employees who might have the best performance and since then, a practical movement was started to increase research on emotional intelligence. According to Goleman, emotional intelligence refers to individuals' ability in controlling and governing themselves and their relationships. He also believes that 80 to 90 percent of individuals' successes can be attributed to emotional intelligence. In defining emotional intelligence for public, Goleman considers it as a form of social behavior (Whitte, 2004).

According to Goleman's definition (1995, trans. By Parsa, 2004), emotional intelligence is classified into five areas of:

- Awareness of one's emotions (self-evaluation and self-esteem).

- Management of the emotions (self-control, trustworthiness, conscientiousness, innovation and adaptability).

- Self-stimulation (progress motivation, optimism and commitment).

- Identification of others' emotions (understanding others, developing others, variety in the influence styles, and political awareness).

- Regulating the relations with others (influence, communication, conflict management, leadership, bonding and participation, collective capabilities).

There have been many studies about the effects of emotional intelligence training upon the constitutive dimensions of emotional intelligence some of which are mentioned here: William et al (2008), Soleimani and Ali-beigi (2009), Pourfaraj (2008), Karademas (2006), RaghibiabdRabbani (2012), Seifi and Pour-mousavi (2010), and Yaryari, Moradi and Yahyazadeh (2007). However, no research was found emphasizing the impact of emotional intelligence training on social capital or the relationship between these two. In addition, the content of emotional intelligence deals with the issues which are important factors in human and social capital. It seems that through training emotional intelligence, human and social capitals can be influenced. In this regard, doing a research on the effects of emotional intelligence training upon the social and human capitals seems necessary. In other words, the aim of this study is to evaluate how emotional intelligence training influences human and social capitals. Based on the intended variables this study aims to examine two following hypotheses:

- Emotional intelligence training has impact upon human capital.

- Emotional intelligence training has impact upon social capital.

\subsection{METHODOLOGY}

This research is a quasi-experimental study with pretest-posttest design and control group. The study's variables include the independent variable of emotional intelligence training and dependent variables of human and social capitals. The research population consists of all the students of Isfahan University of Technology who have been studying in 2012-2013. For sampling, in this study voluntary sampling method with random assignment was used. In this regard, some declarations were designed declaring: emotional intelligence workshops along with the instructor's name, and the time and place of registration. Then, the interested students were invited to participate in the workshop. The sample size was 36 students. They were randomly divided into two groups of the experimental group $(n=18)$ and the control group $(n=18)$.

Criteria for being included in the experimental and control group: a) being a student in Isfahan University of Technology; b) being a student in the academic year of 2012-2013. After sampling, the subjects of both groups were assessed using employability questionnaire. Then, the experimental group received 8 sessions emotional intelligence group training while the control group remained in the waiting list. After the end of the sessions, both groups responded again to the questionnaire. Then, the data obtained from both experimental and control groups were analyzed. For data analyzing, SPSS $_{16}$ software was used. The statistical method used in this study has been 
descriptive statistics including the mean, standard deviation, and inferential statistics including ANCOVA. The format of the sessions is summarized as follows:

The first session: explaining the objectives of the sessions, familiarity with the concept, the position and the necessity of employability.

The second session: familiarizing the members with the concept of emotional intelligence and the components of emotional intelligence.

The third session: informing the members of self-awareness and the factors that prevent one's awareness of his emotions.

The fourth session: familiarizing the members with 5 barriers preventing one's awareness of their emotions and using some alternatives for these barriers.

The fifth session: familiarizing the members with the concept of emotional permeability and that how we can reduce permeability.

The sixth session: members' familiarity with the concept of perception and perception barriers.

The seventh session: members' familiarity with the concept of accepting and expressing emotions, and the barriers of it.

The eighth session: getting feedback from the members on the use and quality of the discussions.

\subsection{RESEARCH TOOLS}

To assess the concept of employability, Mousavi Employability Questionnaire (2013) was used in this study. This questionnaire contains 96 questions that the questions 1 to 6 are related to age, sex, education, job and training experiences, and have been coded by alphabets. Social-capitalrelated questions have been designed in one question that is question 58. The range of scores in this questionnaire is between 57 and 441. Using Likert scale, scoring process was done as follows:

1-Completely agree; 2- Agree; 3- Medium; 4- Disagree; 5- Completely disagree.

It should be noted that for the questions $3,8,32,16,11,33,34,49,50,51$, and 53 scoring was done reversely: 1- Completely disagree; 2- Disagree; 3- Medium; 4- Agree; 5- Completely agree.

Mousavi has evaluated the content validity of the questionnaire using the opinions of specialists, and to assess the convergent construct validity, he has reported the correlation of this questionnaire with employment self-efficacy questionnaire (Salehi, 2005). Using a sample of 20 students of Isfahan University of Technology who have been studying in the academic year of 2012-2013, and using Cronbach alpha, Mousavi, has calculated the reliability of the questionnaire as 0.94 . Cronback alpha reliability of the questionnaire in this study was estimated to be 0.90 through using a sample of 36 students who were studying in Isfahan University of Technology.

\section{DISCUSSION}

Given the purpose and method of the research that is based on comparing the two groups of experiment and control in their scores of employability and its dimensions and considering that it was necessary to control pretest, analysis of covariance (ANCOVA) was used. However, to use this test, its pre-assumptions/defaults have to be examined. In continue, at first, these pre-assumptions will be discussed and then the results of analysis of covariance for the scores of both human and social capitals are provided separately. Table 1 summarizes the results of Kolmogorov-Smirnov and Shapiro-Willkie tests to verify the default normal distribution of scores on the dependent variable (posttest score) and the scores of auxiliary random variable (pretest score).

Table 1. The summary results of the default normal distribution of the dependent variable (posttest score) and the auxiliary random variables (pretest score)

\begin{tabular}{|c|c|c|c|c|c|c|c|c|c|c|c|c|}
\hline \multirow{3}{*}{ The variable } & \multicolumn{6}{|c|}{ Pretest } & \multicolumn{6}{|c|}{ Posttest } \\
\hline & \multicolumn{3}{|c|}{ Kolmogorov-Smirnov } & \multicolumn{3}{|c|}{ Shapiro-Willkie } & \multicolumn{3}{|c|}{ Kolmogorov-Smirnov } & \multicolumn{3}{|c|}{ Shapiro-Willkie } \\
\hline & statistic & $\mathrm{df}$ & Significance & statistic & $\mathrm{df}$ & Significance & statistic & $\mathrm{df}$ & Significance & statistic & $\mathrm{df}$ & Significance \\
\hline Human capital & 0.12 & 36 & & 0.98 & 36 & 0.58 & 0.09 & 36 & 0.20 & 0.98 & 36 & 0.80 \\
\hline Social capital & 0.10 & 36 & 0.20 & 0.98 & 36 & 0.59 & 0.09 & 36 & 0.20 & 0.97 & 36 & 0.52 \\
\hline
\end{tabular}


As it is shown in table 1, the default normal distribution in each of the dependent variables (posttest scores) and the auxiliary random variables (pretest scores) cannot be rejected. Table 2 summarizes the results of the Levine test to examine the default equality of variances of the dependent variable scores (posttest score) and the scores of auxiliary random variable (pretest score).

Table 2. The summary result of Levine test in examining the default equality of variances of the dependent variables (posttest scores) and the auxiliary random variables (pretest score)

\begin{tabular}{|c|c|c|c|c|c|c|c|c|}
\hline \multirow{2}{*}{ The variables } & \multicolumn{4}{|c|}{ Pretest } & \multicolumn{4}{c|}{ Posttest } \\
\cline { 2 - 9 } & $\mathrm{F}$ & $\mathrm{df1}$ & $\mathrm{df} 2$ & Significance & $\mathrm{F}$ & $\mathrm{df} 1$ & df2 & Significance \\
\hline Human capital & 3.63 & 3 & 32 & 0.02 & 1.36 & 3 & 32 & 0.27 \\
\hline Social capital & 5.82 & 3 & 32 & 0.000 & 2.77 & 3 & 32 & 0.06 \\
\hline
\end{tabular}

According to the Levine test (Table 2), the default equality of variances cannot be rejected. Now, given the observance of the default, analysis of covariance can be used.

\subsection{THE RESULTS OF ANALYSIS OF COVARIANCE FOR HUMAN CAPITAL SCORES}

Descriptive statistic results for the pretest and posttest scores of human capital are summarized in table 3 . In the posttest phase, the averages are calculated after controlling the effects of auxiliary random variable.

Table 3. Descriptive statistics of human capital both in pretest and posttest stages

\begin{tabular}{|c|c|c|c|c|c|c|}
\hline \multirow{2}{*}{$\begin{array}{c}\text { Group } \\
\text { belonging of } \\
\text { therapy }\end{array}$} & $\begin{array}{c}\text { Group } \\
\text { belongings } \\
\text { of sex }\end{array}$ & $\begin{array}{c}\text { Sample } \\
\text { size }\end{array}$ & \multicolumn{2}{|c|}{ Pretest } & \multicolumn{2}{|c|}{ Posttest } \\
\cline { 3 - 7 } & & Mean & $\begin{array}{c}\text { Standard } \\
\text { deviation }\end{array}$ & Modified mean & $\begin{array}{c}\text { Standard } \\
\text { deviation }\end{array}$ \\
\hline \multirow{2}{*}{ Experimental } & Male & 13 & 22.23 & 3.83 & 24.25 & 4.98 \\
\cline { 2 - 7 } & Female & 5 & 20.40 & 1.52 & 23.76 & 3.91 \\
\hline \multirow{2}{*}{ Control } & Male & 13 & 22.46 & 4.94 & 21.88 & 4.35 \\
\cline { 2 - 7 } & Female & 5 & 19.00 & 5.29 & 21.11 & 5.03 \\
\hline \multirow{2}{*}{ Total } & Experimental & 18 & 20.31 & 3.41 & 24.01 & 4.71 \\
\cline { 2 - 7 } & Control & 18 & 21.73 & 5.14 & 21.49 & 4.78 \\
\hline
\end{tabular}

As it can be observed in table 3, both in the experimental group and the control group, there have been differences between the pretest and posttest means, but the differences have been more in the experimental group. Good criteria for the means and determining the significance and nonsignificance of the differences are given in figure 


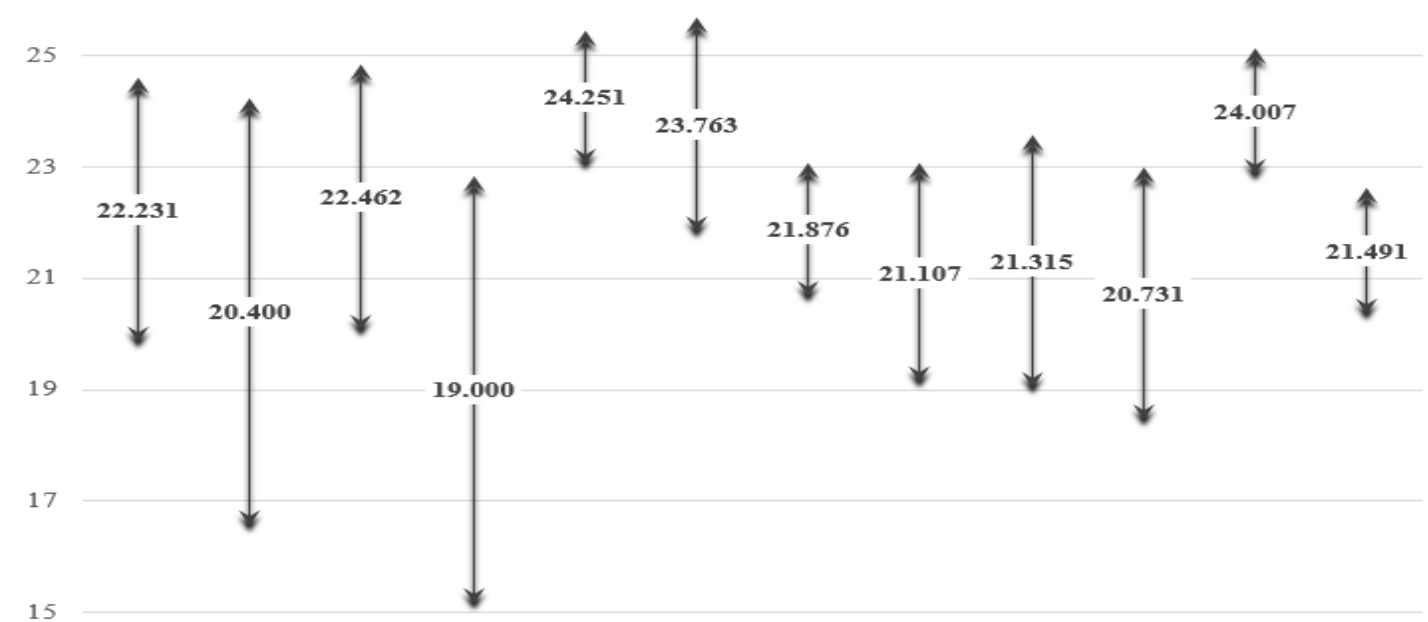

\begin{tabular}{|c|c|c|c|c|c|c|c|c|c|c|c|}
\hline 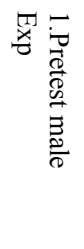 & 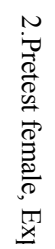 & 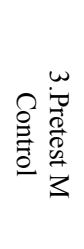 & 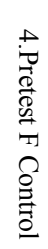 & 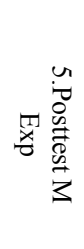 & 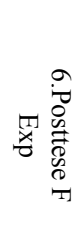 & 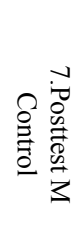 & 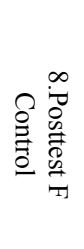 & 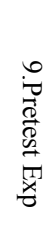 & $\begin{array}{l}\overrightarrow{0} \\
\dot{0} \\
\overrightarrow{0} \\
0 \\
0 \\
0 \\
0 \\
0 \\
0 \\
0\end{array}$ & 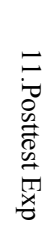 & 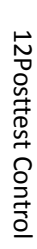 \\
\hline
\end{tabular}

Figure 1. Comparison of human capital means in both experimental and control groups in pretest posttest stages and at the confidence level of $95 \%$. The between-line points represent the averages and the lines' extents show the confidence intervals of the means.

In terms of intergroup comparisons, significance of the differences is shown in figure 1. Combined with the results of the table 4, these differences are discussed in continue:

Table 4. The summary results of covariance analysis to determine intergroup differences in posttest scores of human capital

\begin{tabular}{|c|c|c|c|c|c|c|}
\hline Effect source & $\begin{array}{c}\text { Degree of } \\
\text { freedom (df) }\end{array}$ & $\begin{array}{c}\text { Mean } \\
\text { squares }\end{array}$ & F & $\begin{array}{c}\text { Statistical } \\
\text { significance }\end{array}$ & Effect size & $\begin{array}{c}\text { Statistical } \\
\text { power }\end{array}$ \\
\hline Pretest & 1 & 544.42 & 118.49 & 0.0005 & 0.79 & 1.00 \\
\hline Intervention & 1 & 45.52 & 9.91 & 0.004 & 0.24 & 0.86 \\
\hline
\end{tabular}

According to the results of table 4, human capital posttest significant difference between the two groups of experiment and control $\left(\mathrm{P}=0.004 ; \mathrm{F}=9.91 ; \mathrm{R}^{2}=0.24\right)$ indicates the effectiveness of emotional intelligence on the human capital (the comparison of lines 11 and 12 of figure 1 also suggest the same significant difference). Therefore, the first research hypothesis is confirmed. Emotional intelligence training has been able to predict 24 percent increase in human capital, suggesting the effectiveness of the intervention $\left(\mathrm{R}^{2}>0.10\right)$.

\subsection{ANALYSIS OF COVARIANCE FOR SOCIAL CAPITAL SCORES}

Descriptive statistic results for the pretest and posttest scores of social capital are summarized in table 5. In the posttest phase, the averages are calculated after controlling the effects of auxiliary random variable.

Table 5. Descriptive statistics of social capital both in pretest and posttest stages

\begin{tabular}{|c|c|c|c|c|c|c|}
\hline \multirow{2}{*}{$\begin{array}{c}\text { Group } \\
\text { belonging of } \\
\text { therapy }\end{array}$} & $\begin{array}{c}\text { Group } \\
\text { belongings } \\
\text { of sex }\end{array}$ & $\begin{array}{c}\text { Sample } \\
\text { size }\end{array}$ & \multicolumn{2}{|c|}{ Pretest } & \multicolumn{2}{|c|}{ Posttest } \\
\cline { 3 - 7 } & & Mean & $\begin{array}{c}\text { Standard } \\
\text { deviation }\end{array}$ & Modified mean & $\begin{array}{c}\text { Standard } \\
\text { deviation }\end{array}$ \\
\hline Experimental & Male & 13 & 63.77 & 24.87 & 66.36 & 26.09 \\
\cline { 2 - 7 } & Female & 5 & 79.00 & 9.41 & 61.13 & 11.59 \\
\hline
\end{tabular}




\begin{tabular}{|c|c|c|c|c|c|c|}
\hline \multirow{3}{*}{ Control } & Male & 13 & 72.54 & 29.28 & 67.87 & 29.93 \\
\cline { 2 - 7 } & Female & 5 & 57.60 & 25.88 & 65.47 & 27.62 \\
\hline \multirow{3}{*}{ Total } & Experimental & 18 & 71.39 & 22.51 & 63.75 & 23.03 \\
\cline { 2 - 7 } & Control & 18 & 65.07 & 28.46 & 66.67 & 29.50 \\
\hline
\end{tabular}

As it can be observed in table 5, there have been differences between the pretest and posttest means both in the experimental group and the control group, but the differences have been more in the experimental group. Good criteria for the means and determining the significance and nonsignificance of the differences are given in figure 2:

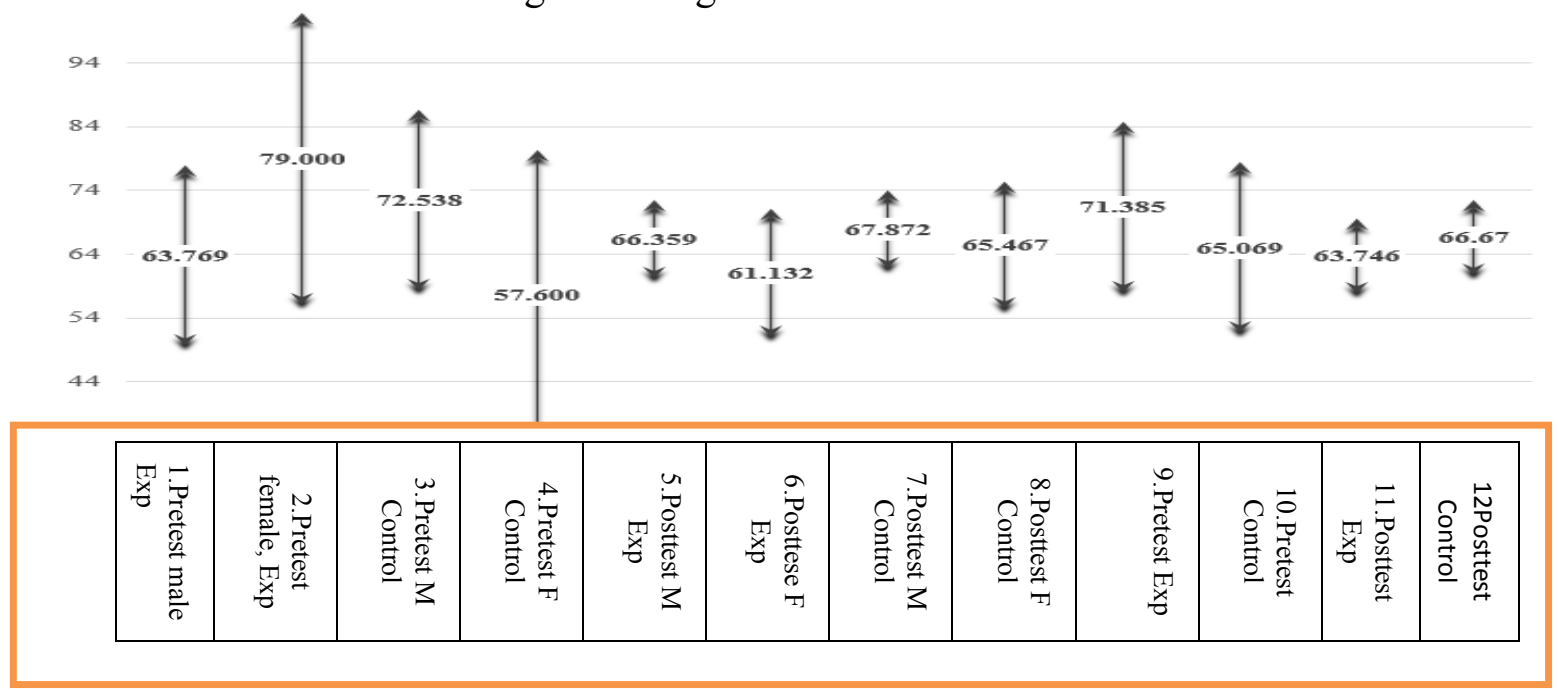

Figure 2. Comparison of social capital means in both experimental and control groups in pretest posttest stages and at the confidence level of $95 \%$. The between-line points represent the averages and the lines' extents show the confidence intervals of the means.

Table 6. The summary results of covariance analysis to determine intergroup differences in posttest scores of human capital

\begin{tabular}{|c|c|c|c|c|c|c|}
\hline Effect source & $\begin{array}{c}\text { Degree of } \\
\text { freedom (df) }\end{array}$ & $\begin{array}{c}\text { Mean } \\
\text { squares }\end{array}$ & F & $\begin{array}{c}\text { Statistical } \\
\text { significance }\end{array}$ & Effect size & $\begin{array}{c}\text { Statistical } \\
\text { power }\end{array}$ \\
\hline Pretest & 1 & 18733.17 & 153.76 & 0.0005 & 0.83 & 1.00 \\
\hline Intervention & 1 & 60.91 & 0.50 & 0.48 & 0.02 & 0.11 \\
\hline
\end{tabular}

According to the results of table 6, human capital posttest non-significant difference between the two groups of experiment and control $\left(\mathrm{P}=0.48 ; \mathrm{F}=0.50 ; \mathrm{R}^{2}=0.02\right)$ suggests the non-effectiveness of emotional intelligence on the social capital (the comparison of lines 11 and 12 of figure 2 also suggests this significant difference). Therefore, this hypothesis is rejected. Emotional intelligence training has been not able to predict the increase in social capital, suggesting the practical noneffectiveness of the intervention $\left(\mathrm{R}^{2}<0.10\right)$.

\section{CONCLUSION}

The results obtained from the analysis of covariance showed that there is a significant difference between the posttest of the experimental group and the control group in terms of human capital. Therefore, it can be concluded that emotional intelligence training has had impact on the human capital of students in the Isfahan University of Technology. Moreover, the results obtained from the analysis of covariance showed that there is no significant difference between the posttests of the experimental and control groups in the social capital. Hence, it can be concluded that emotional intelligence training has had no impact on the social capital of students in the Isfahan University of Technology. 
To explain the first hypothesis, it can be said that regardless of the conducted researches, the effect of emotional intelligence training is evident on the human capital. As mentioned in the methodology part, training pattern of increasing emotional intelligence in this intervention has been based on increasing the dimensions of emotional intelligence. Thus, it is clear that this intervention has had effect on the various aspects of human capital (such as self-awareness, self-regulation, motivation, empathy and social skills), and finally has led to the increase of human capital in this study. It is also noteworthy that the effects of an intervention are measured by its measuring tools. Regarding this study's tools, to measure human capital some questions have been used about emotions control, emotions expression and emotions management. Hence, it is obvious that this intervention has been more effective on human capital.

In the course of this study, as a result of interaction with each other, the members gained new learning during these training sessions. At these sessions, the members defined their experiences with regard to the controlling and expressing their emotions. In this process, members, through observing each other's experiences and integration of assigned duties, gain the ability to manage, know and express their emotions.

To explain the second hypothesis, it can be said that although no research was found on the effect of emotional intelligence training on social capital and the relationship between these two, this non-effectiveness can be explained in this way that by social capital in the Fugate et al model (2004), it means the networks that give influence and information to the individuals and help them to identify and realize career opportunities.

A group of these capitals such as parents, siblings, relatives and so on are with a person at his/her birth, and another group such as school, university, friends and so forth are created over the time. The second group of capitals can be created under the influence of the first group. For example, educated parents can make their children familiar with books or enroll them in high level schools. In this regard, the first group of capitals is to a large extent out of one's control and is controlled by the deterministic powers. The second category of capitals, as it is formed by the first group, is also, to some extent, out of one's control but it cannot be claimed definitely that they are completely out of one's control.

Since these capitals have been established in the individual from years ago and out of the individual's control, they cannot be increased in the process of the intervention. For example, some parts of these capitals are created by media and their contents cannot be changed, or they are established by the family, relatives and friends networks which cannot be influenced directly by the intervention. Hence, this intervention cannot in a short time change or increase the capitals whose processes of creation have been from many years ago.

However, perhaps if the intervention followed up, we could see the effect of the intervention on the increase of such capitals; since, on the one hand, this intervention was itself a social capital and, on the other hand, according to the dimension of social skills in emotional intelligence, the individual sought information, trainings and measures to increase such capitals in oneself, but, due to the limited scope of the study it was impossible for us to do it.

In conclusion, it can be said that the efficacy of an intervention can be measured by its measuring tools. In the employability questionnaire, social capital is measured by such questions as "how much have your parents contributed to the creation of employment opportunities in you?" Since for increasing the scores of these questions, such factors as trainings, family counseling and social capitals should be considered and due to the fact that such trainings were impossible in our intervention, the intervention could not increase the members' social capital.

\section{Acknowledgement}

At the end we express our endless gratitude and indebtedness to all people who help us in this project. In addition, we would like to thank Mr. Roohollah Datli Beigi, M.A. in English Language and Literature, University of Isfahan, whose linguistic and grammatical comments were helpful and constructive in preparation of this paper. 


\section{References}

[1] Dess, G.G., \& Shaw, S.D.(2001). "Voluntary turnover, Social capital, and organizational performance", Academy of Management Review, 26,446-456.Fugate, M. (2006).Employability in the new millennium.In Greenhaus, J. H., \&Callanan, G. A. (Eds.).Encyclopedia of Career Development. Sage: London.

[2] Fugate, M., Kinicki, A. J., \&Ashforth, B. E. (2004). "Employability: A psycho-social construct, its dimensions, and applications", Journal of Vocational Behavior, 65(1), 14-38.

[3] Fugate, M., \&Kinicki, A.J. (2008).“A dispositional approach to employability: Development of a measure and test of implications for employee reactions to organizational change", Journal of Occupational and Organizational Psychology, 81(3), 503-527.

[4] Goleman, D. (1998). Working with Emotional Intelligeace. New York: Ban tam books.

[5] Goleman, D (2004). Emotional Intelligence, Self-awareness, Self-control, Empathy, and Helping Others.Trans. NasrinParsa, Tehran.

[6] Hillage, J. \& Pollard, E. (1998)."Employability: Developing a Framework for Policy Analysis.London: FfEE.

[7] Karademas, E.C. (2006). Self -efficacy, social support and well- being. The mediating role of optimism.Personality and Individual Difterences, 40, 1281-1290.

[8] Nouri-Emamzadeh, A (2009). Emotional Intelligence in the Workplace.Isfahan. Printed.

[9] Pourfaraj-Omran, M (2008). "An Investigation of the Relationship between Innovation, Emotional Intelligence, and self-efficacy".The First National Conference of Creativity, Engineering and Innovation Management.Iran.

[10] Protess, A.(1998). Social capital: Its origins and applications in modern sociology. In J.Hagan\& K.S. cook (Eds), Annual Review of Sociology, 24, 1-24.

[11] Raghibi, M and Rabbani, M (2012)."The Effect of Optimism Skills Training on the Emotional Intelligence of the Boys in Keman Juvenile Institution".The Journal of EducationalPsychological Studies.9 (15): 107-124.

[12] Seibert, S. E., Kraimer, M. L., \&Crant, J. M. (2001). "What do proactive people do? A longitudinal model linking proactive personality and career success", Personnel Psychology, 54(4), 845-874.

[13] Seifi, M. Y. and Pour-mousavi, M (2009). Investigation of the Relationship between Emotional Intelligence and Locus of Control (Internal-External).BA Thesis, Psychology,Payam Noor University of Boroujen.

[14] Soleimani, N and Ali-beigi, F (2009)."Relationship betweenEmotional Intelligence and Selfefficacy of the Managers in the Branches of Islamic Azad University".Journal of Educational Leadership and Management.(10): 137-154.

[15] Whitte, R. (2004). Emotional intelligence and career success among the highly intelligent. Journal of career Assessment.

[16] Yaryari, F. Moradi, A. R. and Yahyazadeh, S (2007)."Relationship of Emotional Intelligence and Control Locus with Mental Health of the Students in the University of Mazandaran".Journal of Psychological Studies.(1): 120-128. 